\title{
KONSELING INDIVIDU DENGAN SIKAP KECANDUAN GAME ONLINE MOBILE LEGEND PADA SISWA
}

\author{
M. Zainal Mustamiin \\ Program Studi Bimbingan dan Konseling, FIP IKIP Mataram \\ E-mail: zainalmustamiin@gmail.com
}

\begin{abstract}
Abstrak: Masalah penelitian ini adalah sikap kecanduan game online yang tinggi, untuk mencegah dan mengurangi kecanduang game online mobile legend, maka siswa kelas VIII di SMP Negeri 10 Mataram perlu diberikan arahan melalui konseling individu. Rumusan masalah dalam penelitian ini adalah: Apakah Ada Pengaruh Konseling Individu Terhadap Sikap Kecanduan Game Online Mobile Legend Di SMP Negeri 10 Mataram Tahun Pelajaran 2018/2019? Sedangkan tujuan penelitian ini adalah untuk mengetahui Pengaruh Konseling Individu Terhadap Kecanduan Game Online Mobile Legend Pada Siswa Kelas VIII Di SMP Negeri 10 Mataram Tahun Pelajaran 2018/2019. Teknik pengumpulan data dalam penelitian ini menggunakan metode angket sebagai metode pokok dan observasi, dokumentasi, dan wawancara sebagai metode pelengkap. Populasi dalam penelitian ini adalah siswa kelas VIII di SMP Negeri 10 Mataram yang berjumlah 93 orang dengan sample berjumlah 7 siswa dari hasil angket yang telah disebarkan dan dihitung dari populasi. Dari hasil penelitian diperoleh Chi Kuadrat sebesar 0,0165 dengan taraf signifikansi $\alpha=0,05$ yaitu $5 \%$ pada df $(7-1) \times(2-1)=6$ sebesar 1,943. Ini artinya Chi Kuadrat lebih kecil dari t-tabel $(0,0165>1,943)$. Yaitu Hipotesis Ho yang diuji diterima dan Hipotesis Ha ditolak. Dengan demikian dapat disimpulkan bahwa: Tidak Ada Pengaruh Konseling Individu Terhadap Sikap Kecanduan Game Online Pada Siswa Kelas VIII Di SMP Negeri 10 Mataram Tahun Pelajaran 2018/2019. Artinya hasil penelitian ini “Tidak signifikan”.
\end{abstract}

Kata Kunci : Konseling Individu, Kecanduan Game Online

Abstract: he problem is that this research is an attitude of high online game addiction, to prevent and reduce the disadventages of online mobile legend games, so grade VIII students at Mataram State Middle School need to be given direction through individual counseling. The formulation of the problem in this study is: Is There and Effect of Individual Counseling on the Attitude of Addiction to Mobile Legend Online Game in Mataram State Middle School 10 2018/2019. Data collection techniques in this study used the questionnaire method as the main methods. The population in this people with a sample of 7 students from questionaires that had been distributed and calculated from the population. From the result of the study obtained Chi Squared of 0.0165 with a significance level of $\alpha=0.05$ which is $5 \%$ in $d f(7-1) x(2-1)=6$ of 1.943 .

This means that Chi Square is Greater that t-table (0.0165> 1.943) Namely the hypothesis that was tested was accepted and the Hypothesis Ha was rejected. Thus it can be concluded that: There is no Effect of Individual Counseling on the Attitude of Online Game Addiction to Class VIII Students in Mataram State Junior High School 10 in Academic Year 2018/2019, Meaning that the results of this study are "Not Significant".

Keyswords: Individual Coundeling, Online Game Addiction

\section{LATAR BELAKANG}

Peneliti tertarik untuk melakukan penelitian dengan memberikan layanan Konseling Individu dengan menggunakan teknik konseling individu terkait tentang "Pengaruh Konseling Individu Terhadap Sikap Kecanduan Game Online Mobile Legend Pada Siswa. Dalam definisi yang lebih luas, Rogers (dikutip dari Lesmana, 2005) mengartikan konseling sebagai hubungan membantu dimana salah satu pihak (konselor) bertujuan meningkatkan kemampuan dan fungsi mental pihak lain (klien), agar dapat menghadapi persoalan/konflik yang dihadapi dengan lebih baik. Rogers mengartikan, "bantuan" dalam konseling adalah dengan menyediakan kondisi, sarana, dan keterampilan yang membuat klien dapat membantu dirinya sendiri dalam memenuhi rasa aman, cinta, harga diri, membuat keputusan, dan aktualisasi diri. Memberikan bantuan juga mencakup kesedian konselor untuk mendengarkan perjalanan hidup klien baik masa lalunya, harapan-harapan, keinginan yang tidak terpenuhi, kegagalan yang dialami, trauma, dan konflik yang sedang di alami klien. 
Game jenis multiplayer online battle arena (MOBA) ini berada dikatagori 'populer' dan sempat menjadi peringkat pertama di play store. Layaknya game moba pada umumnya, ada karakter-karakter yang tentunya menjadi favorit bagi setiap pemain, karna selain memiliki kemampuan yang luarbiasa, juga lebih mudah digunakan. Game yang dirancang untuk smartphone ini memiliki aturan main yang berfokus pada salah-satu dari kedua tim yang berjuang untuk mencapai dan menghancurkan basis musuh sambil mempertahankan basis mereka sendiri untuk mengendalikan jalan setapak, yaitu tiga jalur yang dikenal sebagai top, middle dan bottom. (Bahrul Ulum 2018: 40)

\section{KAJIAN PUSTAKA \\ Konseling Individu}

Pengertian konseling individu

Menurut analisis Shertzer dan stone, definisi-definisi konseling pada umumnya bernuansa kognitif ,afektif, dan behavioral semua definisi konseling mencerminkan relasi dyadic yakni hubngan seorang dengan seseorang, beragam tempat, beragam klien, beragam materi dan tujuan (dalam Wilis. 2009:18)

Wilis (2009: 18) mengatakan bahwa "konseling adalah upaya bantuan yang diberikan seorang pembimbing yang terlatih dan pengalaman, terhadap individu-individu yang membutuhkannya, agar individu tersebut berkembang potensinya secara optimal, mampu mengatasi masalahnya, dan dan mampu menyesuaikan diri terhadap lingkungan yang selalu berubah."

\section{Teknik Konseling Individu}

Sebagai seorang konselor tentu keterampilan sangatlah penting untuk mencapai sebuah hubungan yang dijalin dengan klien agar berjalan lebih baik dan efektif. Jadi dalam penelitian ini peneliti menggunakan Teknik Konseling Individu. Menurut Pearls individu itu selalu aktif dalam keseluruhan. Individu bukanlah jumlah dari bagian-bagian atau organ-organ semata. Individu yang sehat adalah yang seimbang antara ikatan organisme dengan lingkungan (dalam Sofyan 2017: 66).

Adapaun dari tujuan teknik ini ialah untuk membantu individu agar menjadi pribadi yang merdeka dan berdiri sendiri serta dapat terlepas dari Kecanduan Game Online.

a. Langkah langkah konseling individu

1. Membangun Hubungan

Menurut Willis (2009)

mengatakan bahwa dalam hubungan konseling harus berbentuk $a$ working relationship yaitu hubungan yang berfungsi, bermakna dan berguna. Konselor dan klien saling terbuka satu sama lain tanpa ada kepurapuraan. Selain itu, konselor dapat melibatkan klien terus menerus dalam proses konseling. Keberhasilan pada tahap ini akan menentukan konseling selanjutnya.

2. Identifikasi dan penilaian masalah

Sedangkan Namora Lumongga Lubis (2013: 84) apabila hubungan konseling telah terjalin baik, maka langkah selanjutnya adalah mulai mendiskusikan sasaran-sasaran spesifik dan tingkah laku seperti apa yang menjadi ukuran keberhasilan konseling. Konselor perlu memperjelas tujuan yang ingin dicapai mereka berdua. hal penting dalam langkah ini adalah bagaimana konselor dapat mengangkat isu dan masalah yang dihadapi klien. Pengungkapan masalah klien kemudian diidentifikasi dan didiagnosis secara cermat. Seringkali klien tidak begitu jelas mengungkapkan masalahnya, atau iya hanya secara samar menjelaskannya. Apabila hal ini terjadi, konselor harus mendefinisikan masalahnya secara tepat agar tidak terjadi kekeliruan dalam diagnosis.

b. Tujuan Konseling

Seperti yang dijelaskan Yusuf dan Nurihsan (2014: 13) mengatakan bahwa 
tujuan pemberian layanan bimbingan dan konseling ialah agar individu dapat: (1) merencanakan kegiatan penyelesaian studi, perkembangan karir serta kehidupannya di masa yang akan datang; (2) mengembangkan potensi dan kekuatan yang dimiliki seoptimal mungkin; (3) menyesuaikan diri dengan lingkungan sekolah, masyarakat dan lingkungan kerjanya; (4) mengatasi hambatan dan kesulitan dalam studi, penyesuaian dengan lingkungan pendidikan, masyarakat maupun lingkungan kerja.

\section{Kecanduan Game Online}

Pengertian Kecanduan

Kecanduan game online merupakan salah satu bentuk kecanduan yang disebabkan oleh teknologi internet atau yang lebih dikenal dengan internet addictive disorder. Seperti yang disebutkan Young (2000:475) yang menyatakan bahwa internet dapat menyebabkan kecanduan, salah satunya computer game addiction (berlebihan dalam bermain game). Dari sini terlihat bahwa game online merupakan bagian dari internet yang sering dikunjungi dan sangat digemari dan bahkan bisa mengakibatkan kecanduan yang memiliki intensitas yang sangat tinggi.

Kecanduan atau addiction menurut Grispon dan Bokular (Elster, 1999:3) adalah suatu keadaan interaksi antara psikis terkadang juga fisik dari organisme hidup dan obat, dibedakan oleh tanggapan perilaku dan respon yang lainya yang selalu menyertakan sesuatu keharusan untuk mengambil obat secara terus menerus atau berkala untuk mengalami efek psikis, dan kadang-kadang untuk menghindari ketidaknyamanan ketiadaan dari obat.

\section{Ciri Ciri Kecanduan Game Online}

Menurut Masya dan Candra (2016: 156) menjelaskan bahwa terdapat faktor internal dan eksternal yang menyebabkan adiksi terhadap game online. Faktor-faktor internal yang dapat menyebabkan adiksi terhadap game online, sebagai berikut: (1)
Keinginan yang kuat dari diri yang tinggi dalam game online, karena game online dirancang sedemikian rupa agar gamer semakin penasaran dan semakin ingin memperoleh nilai yang lebih tinggi, (2) Rasa bosan remaja yang dirasakan ketika berada di rumah atau di sekolah, (3) Ketidak mampuan mengatur prioritas untuk mengerjakan aktivitas penting lainnya juga menjadi penyebab timbulnya adiksi terhadap game online, (4) Kurangnya self control dalam diri remaja, sehingga remaja kurang mengantisipasi dampak negatif yang timbul dari bermain game online secara berlebihan.

Sedangkan faktor-faktor eksternal yang menyebabkan terjadnya adiksi bermain game online pada remaja, sebagai berikut: (1) Lingkungan yang kurang terkontrol karena melihat teman-temannya yang lain banyak yang bermain game online, (2) Kurang memiliki hubungan sosial yang baik, sehingga remaja memilih alternatif bermain game sebagai aktivitas yang menyenangkan; dan, (3) Harapan orang tua yang melambung terhadap anaknya untuk mengikuti berbagai kegiatan seperti kursus-kursus atau les-les, sehingga kebutuhan primer anak, seperti kebersamaan, bermain dengan keluarga menjadi terlupakan.

Dari penjelasan di atas dapat disimpulkan bahwa faktor-faktor yang mempengaruhi individu adalah: keinginan untuk berinteraksi, terlalu sering bermain game, menjadikan game sebagai pelarian atas masalah yang dihadapi, senang menjadi orang lain, perasaan bangga dan senang saat menjadi hebat dan kuat dalam game.

\section{Cara Mengatasi Timbulnya Kecanduan Game Online \\ Cara mengatasi adiksi internet} menurut Young (Caldwell \& Cunningham, 2010); menjelaskan beberapa cara penanganan game online: (1) Mengurangi waktu bermain game, (2) Membuat jadwal pembagian waktu antara bermain game dan kewajiban, (3) Memberikan dukungan sosial melalui orang atau teman bermain, (4) Terlibat langsung dengan pemain game sehingga mengetahui sejauh mana efek 
ketergantungan terjadi dan menjalin komunikasi yang baik agar tercipta suasana nyaman dan berada dalam kontrol yang baik.

\section{Game Online}

\section{Pengertian Game Online}

Game online merupakan game yang dimainkan menggunakan jaringan internet yang di mainkan banyak orang di mana orang yang bermain game tersebut dapat terhubung satu dengan yang lainnya di mana pemain game online dapat melakukan komunikasi demi mencapai sebuah tujuan antaralain mencapai nilai yang tinggi pada game, mendapatkan hadiah yang sudah ditentukan game tersebut.

\section{Mobile Legend}

Pengertian Mobile Legend

Game online mobile legends: bang bang adalah sebuah game develover dari "moonton" mobile legends: bang bang rilis pada android di China, Indonesia, Malaysia tanggal 11 Juli 2016, dan IOS rilis tanggal 9 november 2016. Genre game ini adalah $M O B A$ yang di design untuk pengguna smartphone dengan tambahan virtual pad. Game jenis multyplayer online battle arena (MOBA) ini berada di kategori 'populer' dan sempat menjadi peringkat pertama di play store. Layaknya game MOBA pada umumnya, ada karakter-karakter yang tentunya menjadi favorit bagi setiap pemain, karenan selain memiliki kemampuan yang luar biasa, juga lebih mudah digunakan.

Game yang dirancang untuk smartphone ini memiliki aturan main yang berfokus pada salah-satu dari kedua tim yang berjuang untuk mencapai dan menghancurkan basis musuh sambil mempertahankan basis mereka sendiri untuk mengendalikan jalan setapak, yaitu tiga jalur yang dikenal sebagai top, middle dan bottom, yang menghubungkan basis-basis.

Dari sini terlihat bahwa game online merupakan bagian dari internet yang sering dikunjungi dan sangat digemari dan bahkan bisa mengakibatkan kecanduan yang memiliki intensitas yang sangat tinggi.

\section{METODE PENELITIAN}

\section{Rancangan Penelitian}

Penelitian ini menggunakan desain penelitian one group test dan post test design dimana dalam rancangan ini hanya ada satu kelompok subyek yaitu kelompok eksperimen sebagai kelompok yang dikenakan perlakuan. Lalu dikenakan perlakuan berupa konseling individu dalam jangka waktu tertentu, kemudian dilakukan pengukuran untuk kedua kalinya yang bertujuan agar mengetahui perbedaan hasil pree test sebelum diberikan perlakuan dengan post test setelah diberikan perlakuan. Gambar 01: One-group pretest-posttest design Sugiyono (2018: 110-111)

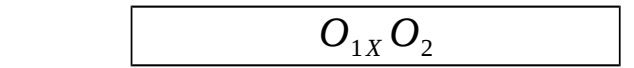

Keterangan:

$O_{1}=$ nilai pretest (sebelum diberi perlakuan).

$\mathrm{O}_{2}=$ nilai posttest (setelah diberi perlakuan).

$\mathrm{X}=$ bahan perlakuan

\section{Populasi Dan Sempel}

Populasi penelitian populasi adalah keseluruhan individu yang dikenai penelitian. Sehubungan dengan penelitian ini yang menjadi populasi adalah seluruh siswa SMP Negeri 10 Mataram Tahun Pelajaran 2018/2019 Kelas VIII yang berjumlah 93 orang.

Tabel 01: Data Jumlah Populasi Kelas VII Di SMP Negeri 10 Mataram Tahun Pelajaran $2018 / 2019$

\begin{tabular}{|c|c|c|c|c|}
\hline \multirow[t]{2}{*}{ No } & \multirow[t]{2}{*}{ Kelas } & \multicolumn{2}{|c|}{ Siswa } & \multirow[t]{2}{*}{ Populasi } \\
\hline & & $\mathrm{L}$ & $\mathrm{F}$ & \\
\hline (1) & (2) & (3) & (4) & (5) \\
\hline 1. & VIII A & 16 & 15 & 31 \\
\hline
\end{tabular}




\begin{tabular}{|c|l|l|l|l|}
\hline 2. & VIII B & 13 & 19 & 32 \\
\hline 3. & VIII C & 12 & 18 & 30 \\
\hline Jumlah & \multicolumn{3}{|l}{} \\
\hline
\end{tabular}

\section{Sampel Penelitian}

Sempel merupakan sebagian dari jumlah populasi atau sebagian subyek yang dapat mewakili populasi itu sendiri. Sugiyono (2018: 118) menjelaskan "sempel adalah bagian dari jumlah dan karakteristik yang dimiliki oleh populasi tersebut". Suharsimi (2014: 174) mengatakan "sempel adalah bagian atau wakil populasi yang diteliti". Terkait dengan penelitian ini, maka teknik pengambilan sempel yang digunakan peneliti adalah purposive sampling. Menurut Sugiyono (2018: 124) mengatakan bahwa sampling purposive adalah teknik penentuan sempel dengan pertimbangan tertentu.

Berdasarkan pendapat di atas sehubungan yang menjadi sempel dalam penelitian ini adalah sesuai dengan teknik purposive sampling. Maka peneliti akan menggunakan sampel sesuai kriteria yang dibutuhkan oleh peneliti

\section{Analisis Data}

Berdasarkan penelitian ilmiah sudah tentu melalui proses analisis data untuk mendapatkan hasil yang representif. Untuk memproses data diperlukan beberapa langkah yang berkaitan dengan subyek dan obyek penelitian dari hasil pengumpulan data melalui angket. Setelah data sudah terkumpul, maka langkah selanjutnya adalah mengelola data/menganalisis data tersebut secara statistik untuk memperoleh hasil yang diharapkan. Adapun statistik yang digunakan dalam penelitian ini yaitu menggunakan teknik analisis Statistik Chi Square sebagai berikut:

Rumus $: \boldsymbol{x}^{2}=\left[\frac{\sum(f o-f e)^{2}}{f e}\right]$

Dimana :

$\mathrm{x}^{2}$ : Nilai Chi Kuadrat

fe : frekuensi yang diharapkan

fo : frekuensi yang diperoleh atau diamati

Adapun langkah-langkah yang ditempuh dalam menganalisis penelitian adalah sebagai berikut:

1. Merumuskan hipotesis nihil (Ho)

2. Membuat tabel kerja

3. Memasukan data kedalam rumus

4. Menguji nilai Chi Square

5. Menarik kesimpulan

\section{HASIL DAN PEMBAHASAN}

Instrumen penelitian ialah suatu alat yang digunakan dalam penelitian untuk mengukur sutu fenomena alam maupun sosial yang diamati untuk memperoleh suatu data yang dibutuhkan dalam kegiatan penelitian, maka diperlukan alat untuk mengumpulkan data. Alat yang digunakan dalam penelitian ini disebut instrumen penelitian. Untuk mengetahui sikap Kecanduan Game Online Mobile Legend digunakan angket tertutup dengan jumlah item 20, masing-masing item disediakan 4 option jawaban, cara pemberian skor menggunakan skala likert dan cara penskoran sebagai berikut : untuk pilihan Sangat setuju diberi skor 4, setuju diberi skor 3, tidak setuju diberi skor 2, dan sangat tidak setuju diberi skor 1. (ridwan, 2013: 12

\begin{tabular}{|l|c|c|c|}
\hline No & $\begin{array}{c}\text { Rentan } \\
\text { g }\end{array}$ & Kategori & $\begin{array}{c}\text { Frekuen } \\
\text { si }\end{array}$ \\
\hline \multicolumn{4}{|c}{5}
\end{tabular}




\begin{tabular}{|c|c|c|c|}
\hline $\mathbf{( 1 )}$ & $\mathbf{( 2 )}$ & $\mathbf{( 3 )}$ & $\mathbf{( 5 )}$ \\
\hline 1 & $61-80$ & Tinggi & 7 \\
\hline 2 & $41-60$ & Sedang & 53 \\
\hline 3 & $20-40$ & Rendah & 33 \\
\hline \multicolumn{3}{|c|}{ Jumlah } & $\mathbf{9 3}$ \\
\hline
\end{tabular}

Penentuan Subjek

Diuraikan populasi dalam penelitian ini berjumlah 93 siswa kelas VIII dan yang menjadi subjek penelitian ini adalah 7 orang siswa kelas VIII SMP Negeri 10 Mataram yang memiliki sikap Kecanduan Game Online Mobile Legend Yang Tinggi Tahun Pelajaran 2018/2019

\begin{tabular}{|c|c|c|c|}
\hline No & Nama (kode) & Jenis Kelamin & Kelas \\
\hline$(1)$ & $(2)$ & $(3)$ & $(4)$ \\
\hline 1 & AI & L & VIIIA \\
\hline 2 & AII & L & VIIIA \\
\hline 3 & HAY & P & VIIIA \\
\hline 4 & SP & L & VIIIB \\
\hline 5 & AWI & P & VIIIB \\
\hline 6 & AAM & L & VIIIC \\
\hline 7 & IBU & L & VIIIC \\
\hline
\end{tabular}

\section{Pengujian Hipotesis}

Dalam penelitian ini, data yang diperoleh berupa angket dianalisis dengan menggunakan rumus Statistik Chi Kuadrat akan tetapi sebelum data-data tersebut dianalisis menggunakan rumus statististik Chi Kuadrat, yang peneliti lakukan terlebih dahulu melakukan tabulasi atas jawaban yang sudah terkumpul. Analisis Statistik Chi Kuadrat dilakukan untuk mengetahui Pengaruh Konseling Individu Terhadap Sikap Kecanduan Game Online Mobile Legend Pada Siswa Kelas VIII Di SMP Negeri 10 Mataram. Adapun langkahlangkah yang dilakukan peneliti dalam menguji hipotesis adalah sebagai berikut.

\section{Membuat Hipotesis Nol}

Untuk analisis statistik, hipotesis alternatif (Ha) yang diajukan pada bab II yang berbunyi: ada Pengaruh Konseling Individu Terhadap Sikap Kecanduan Game Online Mobile Legend Pada Siswa Kelas VIII Di SMP Negeri 10 Mataram Tahun Pelajaean 2018/2019. Maka hal yang lebih dahulu dilakukan adalah mengubah terlebih dahulu kedalam hipotesis nol (Ho) sehingga berbunyi: tidak ada Pengaruh Konseling Individu Terhadap Sikap Kecandun Game Online Mobile Legend Pada Siswa Kelas VIII Di SMP Negeri 10 Mataram Tahun Pelajaran 2018/2019.

\section{Menyusun Tabel Kerja}

Menyusun tabel kerja menyusun simpangan baku atau deviasi pre-test dan post-test dimaksutkan untuk mengetahui deviasi yang akan diperoleh sebelum melakukan dan sesudah melakukan Konseling Individu. Adapun cara menyusun tabel deviasi pre-test dan post-test dapat dilihat sebagai berikut.

\section{Memasukan Data Kedalam Rumus}

Setelah mengetahui kotigensi dari masing masing data pre-test dan post-test, maka langkah yang dilakukan selanjutnya adalah memasukan data kedalam rumus. 
Rumus $: \boldsymbol{x}^{2}=\left[\frac{\sum(f o-f e)^{2}}{f e}\right]$

Dimana :

$\mathrm{x}^{2}$ : Nilai Chi Kuadrat

fe : frekuensi yang diharapkan

fo : frekuensi yang diperoleh atau diamati

$\boldsymbol{x}^{2}=\left[\frac{\sum(f o-f e)^{2}}{f e}\right]$

$x^{2}$

$\frac{0,54}{65,74}+\frac{0,01}{69,88}+\frac{0,39}{69,37}+\frac{0,05}{65,23}+\frac{0,05}{65,23}+\frac{0,}{67}$

$=0,0082+0,0001+0,0056+0,0007+$

$0,0007+0,0012$

$=0,0165$

\section{Menguji Nilai Chi Kuadrat}

Untuk menguji nilai signifikansi nilai chi Kuadrat dalam hasil penelitian ini, setelah diperoleh nilai $x^{2}=0,0165$. Sedangkan $x^{2}$-tabel dengan taraf signifikansi $\alpha=0,05$ pada $d f(7-1) \times(2-1)=6$ menunjukan $x^{2}$ tabel $=1,943$ ini menunjukan bahwa nilai $\left(x^{2}<x^{2}\right.$-tabel) yaitu $(0,0165<$ 1,943). Dengan ini dapat dilihat bahwa hipotesis alternatif (Ha) ditolak sedangkan hipotesis nol (Ho) diterima.

\section{Menarik Kesimpulan}

Dari hasil perhitungan di atas, dimana nilai $\mathrm{x}^{2}=0,0165$ lebih kecil dari nilai $\mathrm{x}^{2}$ tabel sebesar $=1,943$ dengan taraf signifikansi $\alpha=0,05$ yaitu 5\% maka dapat disimpulkan bahwa Hipotesis Nihil (Ho) diterima dan Hipotesis Alternatif (Ha) ditolak, maka kesimpulan penelitian ini adalah: "Tidak Ada Pengaruh Konseling Individu Terhadap Sikap Kecanduan Game Online Mobile Legend Pada Siswa Kelas VIII Di SMP Negeri 10 Mataram Tahun Pelajaran 2018/2019" artinya hasil dari penelitian ini "tidak Signifikan"

\section{PEMBahasan}

Berdasarkan hasil dari layanan Konseling Individu yang dilakukan, menunjukkan tidak adanya adanya gambaran bahwa setiap siwa yang telah mengikuti layanan konseling individu telah memiliki perubahan terhadap Sikap Kecanduan Bermain Game Online Mobile Legend hal tersebut disebabkan oneh faktorfaktor sebagai berikut : mudahnya mengakses internet, kurangnya kontrol orang tua pada anak yang bermain game, mudahnya diberikan apapun yang diinginkan anak tanpa memikirkan resikonya, menyalahgunakan fungsi dari smartphone.

Dapat disimpulkan bahwa teori yang diajukan dalam pembahasan yang selanjutnya dibandingkan dengan hasil analisis yang diperoleh ternyata Hipotesis Nihil (Ho) yang berbunyi : tidak ada Pengaruh Konseling Individu Terhadap Sikap Kecanduan Game Online Mobile Legend Pada Siswa Kelas VIII Di SMP Negeri 10 Mataram Tahun Pelajaran 2018/2019. Diterima, dan Hipotesis Alternatif (Ha) yang berbunyi : Ada Pengaruh Konseling Individu Terhadap Sikap Kecanduan Game Oline Mobile Legend Pada Siswa Kelas VIII Di SMP Negeri 10 Mataram Tahun Pelajaran 2018/2019. Ditolak

\section{KESIMPULAN}

Berdasarkan pembahasan pada bab IV dapat disimpulkan bahwa: tidak ada Pengaruh Konseling Individu Terhadap Sikap Kecanduan Game Online Mobile Legend Pada Siswa Kelas VIII Di SMP Negeri 10 Mataram Tahun Pelajaran 2018/2019. Dengan katalain bahwa hipotesis nol (Ho) diterima dan hipotesis alternatif (Ha) ditolak. Maka dari hasil penelitian ini dapat dilihat nilai terhitung sebesar 0,0165 dan nilai tabel dengan taraf signifikansi $5 \%$ dengan $\mathrm{N}=6$ lebih kecil dari nilai tabel yaitu $(0,0165>1,943)$ sehingga dapat disimpulkan "Tidak signifikan".

\section{DAFTAR PUSTAKA}

Arif Satria Putra Pratama. Hubungan Kecanduan Bermain Game Online Pada Smartphone (Mobile Online Game) Terhadap Prestasi Akademik Mahasiswa Angkatan 2013. Skripsi: Fakultas Lampung

Bahrul Ulum. 2018. Game "Mobile Legends Bang Bang” Di Kalangan Mahasiswa UIN Sunan 
Ampel Surabaya Dalam Tinjauan "One Dimensional Man" Herbert Marcuse. Skripsi: Universitan Islam Negeri Sunan Ampel Surabaya

Desi Ayu Lukmana. Pengaruh Konseling Individu Dengan Pendekatan Rational Emotive Behavior Theraoy Terhadap Penyesuaian Diri Peserta Didik Kelas VIII Mts Al Muhajirin Panjang Bandar Lampung Tahun Pelajaran 2017/2018. Skripsi: Universitas Islam Negeri Raden Intan

Dewi Marianti, 2015 "Hubungan Kecanduan Bermain Game Online Dengan Pola Tidur Dan Motivasi Belajar Anak Usia 10-12 Tahun Di SD Mattoangin 2 Kecamatan Mariso Kota Makasar"

Funk, jhon. (2013) "MOBA, DOTA, ARTS: A brief introduction to gaming's biggest, most impernetrabel genre (https://www.polygon.com/2013/9/2/467292 0/moba-dota-arts-a-brief-introduction-togamings-diggest-most.

Geri Fernando R, 2018. "Hubungan Antara Bermain Game Online Dengan Prilaku Sosial Dan Prestasi Belajar “

Gantina Komalasari. 2018. Teori Dan Teknik Konseling. PT Indeks Permata Puri Media.

IKIP Mataram. 2011. Pedoman Dan Penulisan Karya Ilmiah. Mataram

Juntika nurihsan. 2014. Landasan bimbingan dan konseling. PT. Remaja Rosdakarya. Bandung

Kim. Hyo-Jun. 2002. Improving The Vehicle Performance With Active Suspension Using Road-Sensing Algorithm. Elcevier Sciece Ltd.

Lesmana. 2005. Dasar-Dasar Konseling. Jakarta: Ui Press

Masyah Dan Candra. 2016. Faktor-Faktor Yang Mempengaruhi Perilaku Gangguan Kecanduan Game Online Pada Peserta Didik Kelas X Di Madrasah Aliyah Al Furqon Prabumulih Tahun Pelajaran 2015/2016. Jurnal Bimbingan Dan Konseling. Https://Ejournal.Radenintan.Ac.Id/Index.Ph $\mathrm{p} /$ Konseli

Novita Azis Efendi. 2014. Faktor Penyebab Bermain Game Online Dan Dampak Negatifnya Bagi
Pelajar. Naskah Publikasi: Universitas Muhammadyah Surakarta

Namora Lumongga Lubis. 2013. Memahami DasarDasar Konseling Dalam Teori Dan Praktek. Kecana. Jakarta

Novita Komalasari. Pengaruh Konseling Realita Dengan Menggunakan Teknik Konseling Kelompok Terhadap Kekerasan Fisik Pada Siswa Kelas VIII SMPN Taliwang Kabupaten Sumbawa Barat Tahun Pelajaran 2017/2018. Skripsi: IKIP Mataram

Rahmat Anhar. 2014. Hubungan Kecanduan Game Online Dengan Keterampilan Sosial Remaja Di 4 Game Senter Di Kecamatan Klojen Kota Malang. Skripsi Universitas Islam Negeri Maulana Malik Ibrahim Malang

Ridwan. 2013. Sekala pengukuran variabel-variabel penelitian. Bandung alfabeta.

Sofyan S. Willis. 2017. Konseling Individu, Teori dan Praktek. Alfabeta,cv. Bandung

Syamsu yusuf. 2014. Landasan Bimbingan dan Konseling. PT. Remaja Rosdakarya. Bandung

Sugiyono. 2018. METODE PENELITIAN PENDIDIKAN (Pendekatan Kuantitatif, Kualitatif, Dan R\&D). Alfabeta. Bandung

Www.Cnnindonesia.Com. 2018. Who Akan Masukkan Kecanduan Main Game Jadi 'Kelainan Mental'. Diakases Pada 27/12/2017. 16:05

Winn.B.M Dan Fisher,J.W.2014. Design Of Communication, Competition, And Colaboration In Online Gamers. Dipersentasikan Dalam Computer Game Technologi Confrence.Toronto, Canada. [3 Agustus 2013]

Yuslimar.2012. Efektivitas Layanan Konseling Individual Dalam Mengatasi Kesulitan Belajar Siswa Di SMA Negeri ! Kampar Kabupaten Kampar. Skripsi: Unvesitas Islam Negeri Sultan Syarif Kasim Riau Pekanbaru

Young, K. 2000. Cyber-Disorders: The Mental Health Cocern For The New Millenium. Cyberpsychology \& Behavior, 3(5), 475-479. Www.Netaddiction.Com/Net Compulsions.Htm [2105-2013 